\title{
HR Analytic Competencies: A Comparison of Developed Versus Developing Country HR Practitioner Skill Sets
}

\author{
Chandra Talerico \\ Nathan M. Bisk College of Business, Florida Institute of Technology \\ ctalerico2018@my.fit.edu
}

\begin{abstract}
HR analytic competency are an important pillar for moving HR from transactional to strategic. The value in understanding this skill base across International Human Resource Management is important as HR strategic influence permeates abroad. The study took a segment of the Human Resources Competency Study 360 scores of HR practitioners and data on country developing status from the UN World Economic Situation and Prospects (WESP). This research looked specifically at the HR analytic competency in the context of the practitioner's location - developed versus developing countries. The research also considered where within the organization (e.g. closer to strategic level management) such skills are needed, in assessing the differences in scores from different rater levels (executive vs. non-executive raters). The results indicate that those in developing countries present higher perceived analytic skills on the Human Resource Competency Study than those from developed nations. These and other results regarding rater level are discussed.
\end{abstract}

Keywords: HRCS, analytics, competency, 360 competency rating, HR practitioner 


\section{Introduction}

Much of the research contends that the Human Resources (HR) discipline and competencies have or are moving from administrative to strategic (Lendgnick-Hall et al, 2009; Ulrich, 2008) with concerns and evidence that HR practitioners are not yet meeting the needs of this role to include analytic skills (Sinar. 2018; Maurer, 2018; Ulrich \& Dulebohn, 2015). This move to a strategic partnership view of HR is largely due to the significance of Resource-Based View (RBV) of strategic management. Barney (1995) concluded that HR has increasing importance in the firm, since HR manages the firm human capital resources that contribute to and create competitive advantage. Although the value of RBV in International Business remains a foundational theoretical building block (Autio, Sapienza, Almeida, 2000; Johanson \& Vahlne, 2009), the linkage of HR and function in Multinational Enterprise (MNE) is limited, even though HR practitioners are the coordinator of resources (Farndale, Scullion, \& Sparrow, 2010). Research regarding competencies needed to obtain a competitive advantage through $\mathrm{HR}$ has been robust (Ulrich, Younger, \& Brockbank, 2008, 2012; Ulrich et al. 2012). One of those competencies emergent in the literature is the HR discipline's need to further strategic thinking and data-driven decision making via analytical skills (Ulrich \& Dulebohn, 2015; Giannantonio \& Hurley, 2002; Maurer, 2018; Levenson \& Alexis, 2017). However, much of the focus has been western-centric, and when completed solely outside the US, conclusions are mixed regarding competency needs for International Human Resources Management (IHRM). The literature gap presented here is the lack of analytics skills and competency-based assessment in an international setting that addresses specifically the differences across western and non-western based practitioners, if any. Given that the research on developed and developing countries have conflicting results within the literature, and indicate different HRM needs (exemplified in the literature review to follow on the need for people champions, emotional intelligence, and welfare officers in IHRM) (Welch \& Welch, 2012; Coetzer \& Sitlington, 2013; Han et al., 2006), this suggests a worthy gap to address. 


\section{HRM and Competencies}

In the HR discipline's evolution, the desired skill set has also changed and there are new emerging needs. Kaufman (2014) provides a synopsis of the HRM evolution from a USA perspective drawing upon the labor problem and the emergence of the personnel department and the subsequent timeline to the contemporary era. Kaufman's (2014) dives into the growth of industrial labor economics and labor relations as one path and concurrently personnel management and human relations/ industrial sociology fields as the other path, all of which emerged from the essential "labor problem". This multipath evolution is fermented with the growth of the labor movement, thus demanding different needs from the respective practitioners. In the late 1960s, incorporating organizational behavior in human relations and transition to industrial relations starts to take form. Then, the contemporary models of the more recent HRM field emerge to encompass all segments of relations (human and labor and advance the strategic component of the field). This path and evolution are unique from the history of HRM in developing countries that do not have more than a century of maturity. The "labor problem" that defined western evolution is also not universal. Kaufman's (2014) research describes the problem emerging in 1880 through 1919 timeframe as the "increasingly maladjusted and conflict-prone relationship between employers and employees" (p. 199). The labor problem, not so different in Developing Countries (DC), has other drivers and historical emergence. Tessema and Soeters (2007) describe the "personnel crisis" for Eritrea, a young developing African country, driven by a lack of HRM features that motivate employees and lack adequate reward systems. This type of labor problem equivalent to the USA transitional era HRM practices that emerged from organizational behavior theory (e.g., modern applications of Vroom's expectancy theory and Hersey and Blanchard's model). Subsequently, the focus of HRM needs and roles are driven by this labor problem.

Ayentimi, Burgess, and Brown (2018) describe different drivers for the labor problem and other demands on HRM for Ghana's MNE growth, elucidation of sociocultural systems that influence work behavior uniquely from western systems and thus different implications for HRM. Ayentimi et al. (2018) research suggests different HRM development paths and subsequently different needs from practitioners. Despite HRM development being in various stages and having different evolutionary paths, the 
literature indicates strategic human resource management practices (part of the mature western model) are associated with positive firm performance in non-western settings (Prikshat et al. 2014; Foley, Ngo, \& Loi, 2013). Finally, it is crucial to describe the differences in competencies expectations within HRM. In Kaufman's (2014) umbrella, the strategic HRM model is separated by micro and macro functions. Micro functions handling individual level issues while the macro functions focused on organizational level problems. The competencies and practitioner expectations vary between strategic macro HRM and micro-based HRM, rooted in performance management and organizational behavior skills.

\section{Competency Models}

Competency models provide organizations a means to influence behavior with the expectations such behaviors are associated with maximum performance (Sanchez \& Levine, 2016). HR competency models themselves are abundant and can vary. One broadly accepted model for western practitioners is the Society for Human Resources (SHRM) competency model (Lockwood, et al., 2018). The SHRM model incorporates the multiple functions of HR and the different levels (functional vs. strategic) and suggests the implementation of competencies is dependent on both practitioner career position and function (i.e., utilization of competencies to make strategic decisions will happen more so with an executive or senior-level HR professional). SHRM also suggests, in their global membership, that the model supports practitioners from all locations. The nine competencies include: leadership \& navigation, business acumen, ethical practices, relationship management, consultation, critical evaluation, global and cultural effectiveness, and communication. The critical evaluation competency requires measurement and assessment skills, problem-solving, and research methodology in part by analytic behaviors. Additionally, the business acumen competency comprises subcompetencies in HR and organizational metrics, analytics, and business indicators (SHRM, 2016).

On the academic side of the house, Ulrich and colleagues have studied HR competencies extensively, exposing the gaps in skills as well as emerging competency needs (Ulrich \& Dulebohn, 2015; Ulrich, Younger, \& Brockbank, 2008, 2012; Ulrich, et al., 2012). Ulrich et al. (2015) provide a synthesis of the competency research into six core domains: business (e.g. business acumen, business partner); personal (ethics, selfawareness, trusted); HR tools, practices and process (talent management, employee 
engagement); HR information system and analytics (data driven mindset, process excellence); change (change leader, collaborative, resolver of issues, be business psychologists); and organizational and culture (culture leader/ champion, organizational design). Ulrich et al.'s (2015) is an umbrella model that incorporates academic, professional association, and industrial research models to define a robust synthesis to bring together a cohesive understanding of HR competencies. The literature also indicates the demands of HR competencies and availability of needed skills vary by country. Mamman and Al Kulaiby (2014) suggest that the strategic partner role is the least performed in the developing country of Sultanate Kingdom of Oman. The research can also be conflicting. Ulrich et al. (1995) found an increased need for business knowledge outside the United States, while Han et al. (2006) found contrary evidence in a Taiwanese high technology company finding no evidence for business knowledge competency demand. Welch and Welch (2012) research indicated predominantly organizational behavior and operational HR based skill demand, such as a "welfare officer," for HR practitioners supporting international projects. Likewise, Coetzer and Sitlington (2013) suggest a need for knowledge, skills, and attitudes (KSA) in emotional intelligence over intellectual skills. This research indicates an HR competency model with analytic skills, business acumen, and technology needs to be studied for universality since some skills may not have the same weight as or even need in an IHRM setting. However, there is also research that indicates value and alignment with the western model abroad for HR competencies, including strategic HRM in India (Subramaniam \& Nankervis, 2013).

\section{HR Analytics}

The skill embedded in strategic and business acumen competencies, and of most interest to this study, is that of one emergent within the discipline - analytic skills. The parameters of analytics must be defined to understand the interest. According to Bassi (2010) HR analytics is "the application of a methodology and integrated process for improving the quality of people related decisions for the purpose of improving individual and/or organizational performance" (p.11). Research is consistent regarding the different types of business analytics, and the framework is presented similarly for HR analytics in Eubanks (2019), Lunsford and Phillips (2018), and Soundararajan and Singh (2016). Soundararjan and Singh's (2016) however, provide a continuum that provides a clear and concise visual explanation: 


\section{Figure 1}

Depiction of Soundararjan and Singh's (2016, p. 9) continuum of data analytics with explanations of data value. As displayed, the value of analytics to the firm and complexity advance concurrently.

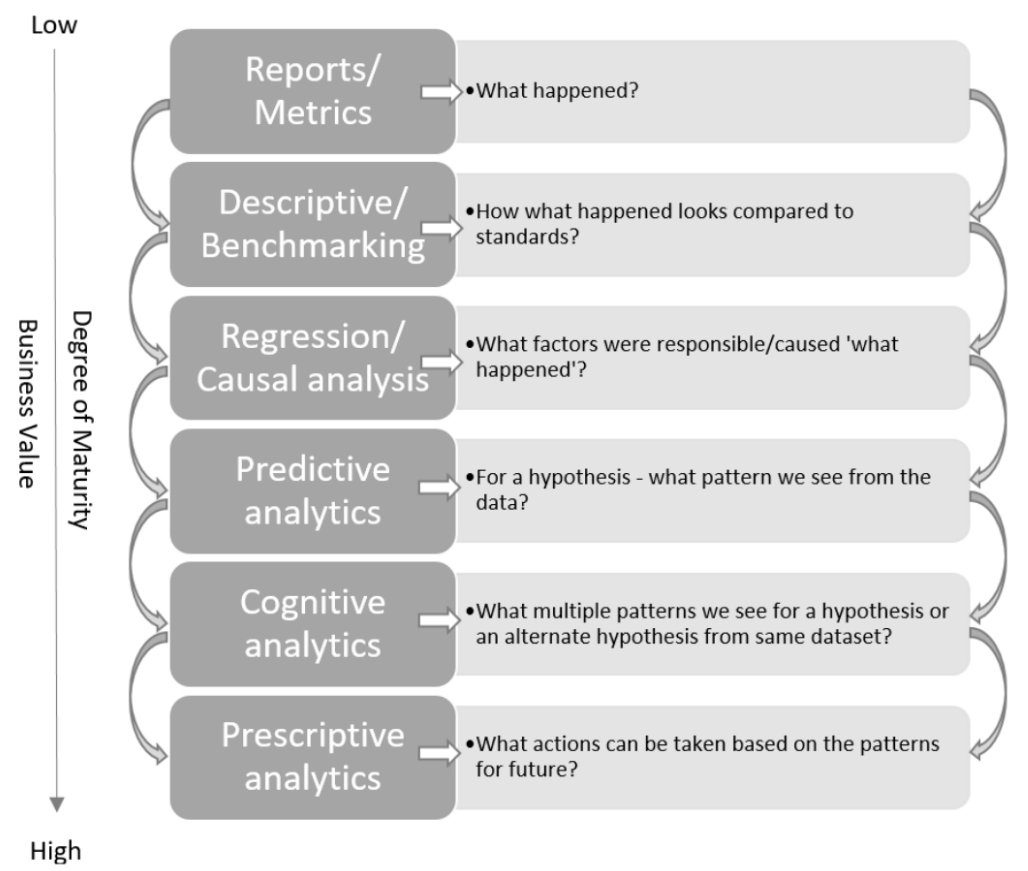

As one can see from the continuum, the goal of analytics is to inform business decisions and prescribe the best actions for the firm and as one advances within the framework toward higher maturity, more value is obtained from the firm (Soundararajan \& Singh, 2016).

Despite decades of research and availability of metrics and business intelligence growth, the HR analytic skill set has emerged as valuable in recent literature because of the availability of big data, the growth of Human Resource Information Systems (HRIS), and the ability to leverage this information more readily in the agenda to push HR beyond transactional administrative processes to improving business performance through 
predictive analytics (Fitz-enz, 2010). HR practitioners have products available for a myriad of applications for the different HR functions - Applicant Tracking Systems, Learning Management Systems, and core HR functions, such as payroll and benefits administration (Eubanks, 2019). However, the incorporation of analytics has been a long and bumpy road. Despite the need for HR practitioners to utilize data to make strategic decisions, the buy-in and codification has not been well received, even with the early insights of Jac Fitz-enz (LaFevor, 2018; Caudron, 2004). The limited literature on analytic skills suggests the skill is lagging/lacking despite the firm's needs (Vargas et al., 2018). Practitioner competency preparation research also indicates that HR specific graduate programs do not prepare students and business-based models (e.g. Masters of Business Administration) in providing competency capabilities in strategic contribution, business knowledge, and HR technology skills (Scanlan, 2007). Vargas et al. (2018) identified barriers to the adoption of analytics to include quantitative and technology selfefficacy, in addition to attitude toward the innovation and gender. The incongruence of interest in the skill, demand, and desire begs one to understand why practitioners are not diving into the analytics deep end of the pool. The difference may lie within the HRM system. The variance in HRM development across non-western countries and literature regarding skill need and the value of analytic skills in IHRM is not well known. Further, the lack of analytic skills in international empirical competency studies, suggests an interest to advance what Kaufman (2014) describes as micro HRM; the focus on human relations functions to continue to solve conflict and concentrate on the organization and culture competencies related skills in IHRM environments (Welch \& Welch, 2012; Han et al., 2006). Despite barriers, Kryscynski et al. (2017) defends that such analytical skills will enhance decision making, increase influence of the HR function, generate greater insights, and further HR practitioner ability to speak the language of the firm (numbers and data). Kryscynski et al.'s (2017) results are promising, regarding analytical skill value for practitioners, producing support for their hypothesis that higher analytical abilities will have higher perceived job performance. The study was global in nature, but did not explore the potential differences between countries. In the camp of support for more business acumen and strategic decision capabilities, Wright et al. (2001) research suggests HR professionals are not living up to the expectations of the firm; executives do not find the function as effective as the practitioners perceive their value to be.

Analytics is a quagmire - the HR field finds value and has championed for 
analytics growth, a desire to incorporate numbers into the language of $\mathrm{HR}$, and strive for more effective influence on the $\mathrm{C}$-suite; meanwhile, the resistance and continued interest to solve the intangible costs of culture, communications, and conflicts seems to have a foothold on the field and literature. This intangible demand in the literature for microHRM is based on the firm's continued need to ensure people are working together like a well-oiled machine. More information is needed during this dynamic period in HR to determine the final place analytics will have on the HR competency plate, and if the promises of value will be ubiquitous in IHRM.

\section{Why developing countries?}

IHRM will become more influential in HRM development if firms continue to melt across borders (Schuler \& Jackson, 2005). However, key themes in international business (IB) research that may influence HRM, are not well incorporated into the competency literature, nor is there an understanding of the right competency ratio in the context of IB fully considered for the HR practitioner. Following the same vein as Ulrich et al. (2015), describing competencies as falling into "food groups," this research assumes, similar to the nutritional plate guidelines, that not all competencies need the same portion size. Furthering this hypothetical argument, this research considers the concept that desired portions and guidelines change, depending on where you live (e.g., World Health Organization, European Network for Public Health Nutrition, United States Department of Agriculture all have different guidelines for the basic food groups). Taking this logic, and the volume of research in IB regarding culture, conflict, and cognition (Griffith, Cavusgil, \& Xu, 2008), the value of HR practitioners to bridge these issues may be more valuable to the international firm than a strategic business partner, and thus may have a more significant portion of the IHRM plate recommendation. This logic is fitting with advancing the internationalization process model (revised 2009 Uppsala model), where learning and commitment are agents for exploiting opportunities abroad and a key to successful growth abroad (Johanson \& Vahlne, 2009). In IB, internationalization's hurdle is rooted in overcoming certain features, such as cultural and psychic distance. When HR practitioners are utilizing their skills in organizational change and culture, communication, and act as a change agent to increase learning, creating, and trustbuilding as presented in the competency models (Ulrich et al., 2015) their value essentially grows in the context of the Uppsala model to reduce the liability of foreignness, given the criteria for change are the functions of learning, creating, and trust- 
building (Johanson \& Vahlne, 2009). Now, if one thinks about the practitioner's role, combined with the growth of foreign direct investment in DCs, the competency mix and demand may be influenced, and the needs for analytic skills may be washed away as the firm looks to overcome obstacles that HR practitioners are primed to help solve. Thus this potential drives value in understanding the difference in analytic skills between developed and developing countries. The value of considering HR competency across all recommended guidelines becomes more evident, especially emerging firm locations that will become more influential to firm success and a one-size-fits all approach may not be pragmatic. Firms abroad must address global staffing and local-national issues utilizing modern practices with reliance on local leaders, versus former expensive methods of using expatriates, to manage the firm and remain competitive (Schuler $\&$ Jackson, 2005).

\section{Theory Development \& Hypotheses}

To further the HRM competency model discussion regarding analytic skills, this research finds value in understanding the differences of the practitioner skills between developed and developing nations. This study will provide context for MNE firms when considering their capabilities and development needs for strategic HRM and business-based decision making. The research will fill a gap by providing a comprehensive more generalizable analysis. In contrast, previous competency research based on a single country was limited in scope to that country (e.g. Sultanate Kingdom of Oman and Eritrea) (Mammam \& Al Kulaiby, 2014; Tessema \& Soeters, 2007). Furthermore, this information will also inform whether the agenda to move HR to becoming more of a business partner has penetrated equally or if the need is focused in developed countries where technological and innovation resources are abundant and provide practitioners more capabilities to move to these mature functions of HRM according to the western framework. Also, it will be beneficial to know if the current competency models are globally relevant, as previously assumed. Ayentimi et al. (2018) work indicate least developed countries have practitioners who are in a nascent stage of development, the lack of education and professional affiliations along with the demand to sew together a unique socio-cultural perspective of work, all of which indicates that practitioners would not present with and utilize analytics. Similarly, Han et al. (2016), suggests that practitioners in an international setting are focused on keeping teams working cohesively, functioning as change agents and that those skills provide more 
value to the firm than analytics. Driving analytics requires the availability of certain resources and compass an innate need for data. According to Fitz-enz (2010) this information comes from an HRIS; however, there is an assumption that such a system is in place, and electronic HRM is embedded in the firm. These systems can be costly, and for DCs one of the key characteristics is the lower economic status (UN, 2019). Additionally, research into the implementation of electronic HRM for those who work as employee champions is low versus business partners, which is high (Voermans \& Veldhoven, 2007). The linkage made between DC practitioners in roles more closely associated with employee champions, and the limited availability of financial resources further drives the rationale behind $\mathrm{H} 1$.

Given the research suggest that practitioners in DCs are valued for and play more of an employee champion role (vs. a business partner), the groundwork is in place for the first hypothesis:

H1- Practitioners in developing countries will seek and utilize analytics less than practitioners in developed countries.

The roles and responsibilities of the practitioner should not be ignored. According to SHRM's model, the needs and demands of critical thinking and strategic skills demand shift and become more evident in more senior roles (SHRM, 2016). The industrial buzz is around support for the $\mathrm{C}$-suite and business decisions. This logic aligns well with higher acceptance of electronic HRM for practitioners who describe being in a business partner role (Voermans \& Veldhoven, 2007). Kryscynski et al. (2017) found no significant relationship with job level and analytical skills. Their hypothesis was based on the presumption leaders would give the tasks to lower-level practitioners. However, this logic doesn't align with where the demand for conducting such analysis nor aligns with where the capabilities are expected within the competency models (Lawler \& Boudreau, 2013; SHRM, 2016). According to Lawler and Bordeaux (2017) the research has repeatedly documented that those who utilize analytic frameworks play a more substantial strategic role within the organization. Furthermore, the ability to identify the right questions needs to come from those familiar with the problems. Therefore, job level may not be relevant, but relational status to strategic decision making and function becomes important. This research seeks to understand if those being evaluated by executives (and thus supporting strategic business decisions) would be 
utilizing the necessary analytic skills to support strategic HRM. Therefore, rather than utilize job level, this research considered the rater's strategic position as the beacon for skill presence and strength in skill use given the proximity to where the need exists within the firm. If the previous hypotheses are supported, though, we should expect to see a negative modifying effect for practitioners from DCs, given limited economic resources and general demand for DC practitioners to solve organizational behavior based problems.

H2a-Practitioner perceived analytic ratings will be positively related with executive level raters

$H 2 b$-Practitioner DC status will negatively partially modify the perceived analytic scores from executive level raters

The resulting model from this hypothesis set views as follows:

\section{Figure 2}

Hypothesis model for the effect of DC status, executive relationship, mediation effect of DC status on perceived practitioner analytic performance.

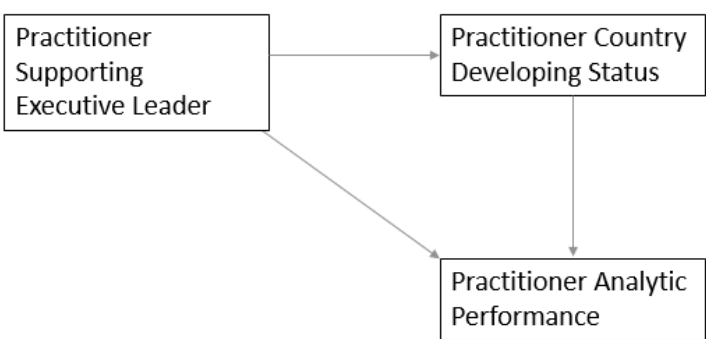




\section{Methods}

This research borrows from the dataset of the Human Resource Competency Study (HRCS) to perform this analysis. The HRCS was the most suitable to meet the needs of this research to spans the different nations (developed, developing). Despite the robust nature of the HRCS study the results have not been analyzed for the impact of country on analytic competency results. The HRCS also is a desirable dataset because the format provides insight from within HR and executive stakeholders of which the 360 rater format is well suited to accomplish. According to Kryscynski et al. (2017), this is the largest single database of the global HR professional and associate competency ratings. The reputation, longitude, and broad use of the survey speaks to its acceptance and validity (Kryscynski et al., 2017; Ulrich et al., 2015). The HRCS is conducted as a 360 survey, meaning participants rate themselves as well as those familiar with their performance above (superior), beside (colleagues), below (reporting employees), as well as customers (non-HR associates and other individuals). As such, these scores and the results are the perceived skills from the practitioner's raters in their respective roles. The available sample size at the time of the study from the HRCS included 31,868 respondents, of which 3,964 were HR practitioners that rated themselves and 27,904 who then rated those individuals. As spoken to previous studies that have utilized the dataset, the dataset's limitations include the inability to track response rates and the potential for response bias toward highly motivated and successful HR professionals (Kryscynski et al., 2017). Despite this limitation, this being a comparative analysis, and the potential bias being universal to all participants, relativity would not be impacted. Additionally, the robust sample size provides increased statistical power (Fraley \& Vazire, 2014).

The overall survey was 123 items, 5-point Likert scale. However, for this analysis, the analytics subset of questions was utilized. According to Kryscynski et al. (2017), the analytics question set has conceptual overlap with the LAMP framework. The LAMP framework addressed broadly analytic skills across the Boudreau and Ramstad's (2007) defined categories of: 1) Logic - ensuring a clear causal logic connecting measures and relevant business outcomes, 2) Analytics - engaging analysis that clearly tests relationships between measures and outcomes, 3) Measures - identifying the right data and ensuring high- quality data, and 4) Process - ensuring a process for incorporating the insights from rigorous analytics into business decision making (Boudreau \& Ramstad, 2007). The LAMP framework is intended to drive decision science from the HR 
organization, and their work follows a consistent modeling progression of analytics toward informing and prescribing business decisions, as found in Eubanks (2019), Lunsford and Phillips (2018), and Soundararajan and Singh (2016). Research supports LAMP's value within the HR organization from a strategic perspective; those who utilize elements of the framework play a stronger strategic role within the firm (Lawler \& Boudreau, 2015). In addition to the analytic question set, demographic and control variable data was also acquired from the survey. The rater category (HR associate, nonHR associate, other, self, superior, and subordinate), country, nature of the firm (nongovernment organization, privately owned for-profit, publicly-traded for-profit, college or university, government organization, other non-profit organization, and public-private partnership), business type (stand-alone, business unit of a larger multi-unit company, independent operating company that is a wholly-owned subsidiary of a larger company, joint venture), rater business function (e.g., HR, Engineering, Marketing, Operations, etc.), rater level (entry, executive, management, non-supervisory employee, other, supervisor, top executive), education, and sex.

Kryscynski et al. (2017) identified this final question set from the HRCS for analytic competency through several robustness checks, including assessments for covariance between analytical ability and one's general abilities. Krycsynski et al. (2017) conducted exploratory (EFA) and confirmatory (CFA) factor analyses to aggregate the full dataset into three latent factors - analytic ability, general business skills, and personal credibility, of which general business skills and personal credibility questions were not used for this analysis. Krycsynski et al. (2017) also utilized aggressive factor cutoffs of 0.80 with a cross-loading maximum of 0.40 to maximize the discriminant validity of the factors. The final question set had a Chronbach's alpha of .94, suggestive of robust internal reliability in Kryscynski et al.'s (2017) analysis. Their analysis concluded a strong fit for assessing analytic competency, and as such, the same instrument set was utilized for this study.

The questions utilized from HRCS were formulated as follows:

1) Translates data into useful insights for the [Organization's name]

2) Identifies [Organization's name] problems that can be solved with data

3) Uses data to influence decision making in [Organization's name]

4) Effectively uses HR analytics to create value for [Organization's name] 
5) Identifies important questions about the organization that can be answered with data

6) Accurately interprets statistics

Country data from the survey was taken and then coded based on the World Economic Situation and Prospects (WESP) published by the United Nations (UN, 2019). This report classifies countries into three broad categories: developed economies, economies in transition, and developing economies, representing basic economic country conditions. The report has also identified least developed (LDC), which were also incorporated into the coding of the countries in this analysis. LDC was added to control for the classification's potential impact since these countries demonstrated more vulnerability or were extensively remote or small in size. Also, the 2018 GNI per capita for the country data was captured from The World Bank's most recent data file (The World Bank, 2020). The results on the survey utilized for this analysis, for the country of practitioner origin, was completed by the assessor, not the participant. The developing status was coded as follows: least developed -1 , developing -2 , transition -3 , developed -4 .

Baron and Kenny (1986) moderator methodology was employed to test the moderation within the model. Each model was measured independently for significance and then combined to discern the interactive effects. The expectation is both rater level (practitioner supporting executive leaders) and the country developing status will impact the DV perceived 360 analytic scores by the rater. Additionally, the interaction of being in a developing status will negatively moderate perceived analytical scores for practitioners who receive executive 360 scores. The Hayes PROCESS v. 3.4 macro tool for SPSS was used to generate the results of the interaction analysis.

\section{Results}

As part of robust checks the 6 question scale for analytic skills was assessed in SPSS for internal validity and the Cronbach's Alpha was .938. This score was considered high and consistent with Kryscynski et al.'s (2017) Cronbach's Alpha of .94. The means, standard deviations, and correlations are provided in the first table. 
3rd International Conference on BUSINESS,

MANAGEMENT AND FINANCE

OXFORD, UNITED KINGDOM

\section{Table 1}

Means, standard deviations, and correlations

\begin{tabular}{|c|c|c|c|c|c|c|c|c|c|c|c|c|c|c|c|c|c|c|c|}
\hline $\begin{array}{l}\text { Variable } \\
\end{array}$ & $n$ & $M$ & $S D$ & 1 & 2 & 3 & 4 & 5 & 6 & 7 & 8 & 9 & 10 & 11 & 12 & 13 & 14 & 15 & 16 \\
\hline 1. Rater Category & 31868 & 3.19 & 1.83 & & .01 & $.06^{* *}$ & $.04 * *$ & .02 & $-.05 * *$ & $-.12^{* *}$ & $.03^{* *}$ & .01 & $.04^{* *}$ & .00 & .01 & .01 & -.01 & $-.02^{*}$ & .01 \\
\hline 2. Region & 31737 & 3.14 & 2.12 & .01 & - & $.14^{* *}$ & $-.05^{* *}$ & $.13^{* *}$ & $-.14^{* *}$ & $-.06^{* *}$ & .00 & $-.05 * *$ & -.01 & $.02^{*}$ & $.06^{* *}$ & $.05^{* *}$ & $.03^{* *}$ & 0.01 & $.04^{* *}$ \\
\hline 3. Country Developing Statt & 31444 & 2.79 & 1.03 & $.06^{* *}$ & $.14^{* *}$ & & $.58^{* *}$ & $.16^{* *}$ & $-.31^{* *}$ & $-.05^{* *}$ & $-.07^{* *}$ & $-.12^{* *}$ & -01 & $-.06^{* *}$ & $-.02^{*}$ & $-.02^{*}$ & $-.07^{* *}$ & $-08^{* *}$ & $-03^{* *}$ \\
\hline 4. GNI & 30669 & 37914.06 & 24698.5 & $.04 * *$ & $-.05^{* *}$ & $.58^{* *}$ & - & $.11^{* *}$ & $-.21^{* *}$ & -.01 & $-.05^{* *}$ & $-.08^{* *}$ & $.05^{* *}$ & $-.03^{* *}$ & .02 & .01 & $-.04^{* *}$ & $-.05^{* *}$ & .00 \\
\hline 5. Organization Nature & 28748 & 2.96 & 1.2 & .02 & $.13^{* *}$ & $.16^{* *}$ & $.11^{* *}$ & - & $-.18^{* *}$ & $-.06 * *$ & $-.05^{* *}$ & $-.06 * *$ & $.07^{* *}$ & .02 & $.03^{* *}$ & $.03^{* *}$ & .00 & .00 & $.02^{*}$ \\
\hline 6. Organization Type & 28652 & 2.03 & 0.94 & $-.05^{* *}$ & $-.14^{* *}$ & $-.31^{* *}$ & $-.21^{* *}$ & $-.18^{* *}$ & - & $.07^{* *}$ & $.02^{*}$ & $.11^{*}$ & -.01 & $.04^{* *}$ & $.03^{* *}$ & $.04 * *$ & $.05^{* *}$ & $.06 * *$ & $.05 * *$ \\
\hline 7. Rater Function & 16384 & 8.55 & 3.03 & $-.12^{* *}$ & $-.06^{* *}$ & $-.05^{* *}$ & -.01 & $-.06 * *$ & $.07^{* *}$ & - & $-.04^{* *}$ & .02 & $-.16^{* *}$ & .01 & .01 & .00 & .00 & .01 & .01 \\
\hline 8. Rater Level & 18264 & 3.53 & 1.4 & $.03^{* *}$ & .00 & $-.07^{* *}$ & $-.05^{* *}$ & $-.05^{* *}$ & $.02^{*}$ & $-.04^{* *}$ & & $-.03^{* *}$ & $.05^{* *}$ & $.04 * *$ & $.04^{* *}$ & $.05^{* *}$ & $.05^{* *}$ & $.06^{* *}$ & $.04^{* *}$ \\
\hline 9. Education & 17569 & 6.42 & 1.52 & .01 & $-.05^{* *}$ & $-.12^{* *}$ & $-.08^{* *}$ & $-.06 * *$ & $.11^{* *}$ & .02 & $-.03^{* *}$ & - & $-.04^{* *}$ & .00 & .00 & -.02 & $-.02^{*}$ & $-.03^{* *}$ & -.01 \\
\hline 10. Sex & 18294 & 1.54 & 0.5 & $.04 * *$ & -.01 & -.01 & $.05^{* *}$ & $.07^{* *}$ & -.01 & $-.16^{* *}$ & $.05^{* *}$ & $-.04^{* *}$ & - & $.03^{* *}$ & $.02^{*}$ & $.03^{* *}$ & $.02^{*}$ & $.04 * *$ & $.04 * *$ \\
\hline 11. Question 1 & 28540 & 4.03 & 0.73 & .00 & $.02^{*}$ & $-.06^{* *}$ & $-.03^{* *}$ & .02 & $.04^{* *}$ & .01 & $.04^{* *}$ & .00 & $.03^{* *}$ & $\therefore$ & $.74^{* *}$ & $.72 * *$ & $.72^{* *}$ & $.68^{* *}$ & $.62^{* *}$ \\
\hline 12. Question 2 & 28173 & 4.06 & 0.75 & .01 & $.06^{* *}$ & $-.02^{*}$ & .02 & $.03^{* *}$ & $.03^{* *}$ & .01 & $.04^{* *}$ & .00 & $.02^{*}$ & $.74^{* *}$ & & $.82^{* *}$ & $.76^{* *}$ & $.70^{* *}$ & $.64^{* *}$ \\
\hline 13. Question 3 & 28108 & 4.02 & 0.77 & .01 & $.05^{* *}$ & $-.02^{*}$ & .01 & $.03^{* *}$ & $.04^{* *}$ & .00 & $.05^{* *}$ & -.02 & $.03^{* *}$ & $.72^{* *}$ & $.82^{* *}$ & 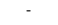 & $.79^{* *}$ & $.73^{* *}$ & $.66^{* *}$ \\
\hline 14. Question 4 & 26914 & 3.92 & 0.79 & -.01 & $.03^{* *}$ & $-.07^{* *}$ & $-.04^{* *}$ & .00 & $.08^{* *}$ & .00 & $.05^{* *}$ & $-.02^{*}$ & $.02^{*}$ & $.72^{* *}$ & $.76^{* *}$ & $.79^{* *}$ & - & $.75^{* *}$ & $.66^{* *}$ \\
\hline 15. Question 5 & 27459 & 3.96 & 0.82 & $-.02^{*}$ & .01 & $-.08^{* *}$ & $-.05^{* *}$ & .00 & $.06^{* *}$ & .01 & $.06^{* *}$ & $-.03^{* *}$ & $.04^{* *}$ & $.68^{* *}$ & $.70^{* *}$ & $.73^{* *}$ & $.75^{* *}$ & - & $.67^{* *}$ \\
\hline 16. Question 6 & 27908 & 4.03 & 0.74 & .01 & $.04^{* *}$ & $.03^{* *}$ & .00 & . $.02^{*}$ & $.05^{* *}$ & .01 .01 & $.04^{* *}$ & -.01 & $.04^{* *}$ & .62** & $.64^{* *}$ & $.66^{* *}$ & $.66^{* *}$ & $.67^{* *}$ & \\
\hline
\end{tabular}

Then, because of the value in understanding the difference in perceived analytic skill score means across different countries and regions, the means are providing in Table 2. This table presents the countries by their defined region as prescribed in the World Bank data set. Regions that present with the high scores include those with a higher propensity of least developed and developing countries are Sub-Saharan Africa and the Middle East and North Africa. This will become more evident in the regression models. 


\section{3rd International Conference on BUSINESS,}

MANAGEMENT AND FINANCE

OXFORD, UNITED KINGDOM

Table 2

Mean scores by country and region

\begin{tabular}{|c|c|c|c|c|c|c|c|}
\hline $\begin{array}{l}\text { Country and } \\
\text { Region }\end{array}$ & Q1 & $\mathbf{Q 2}$ & $\mathbf{Q 3}$ & Q4 & Q5 & Q6 & $\begin{array}{l}\text { Aggregate } \\
\text { Average }\end{array}$ \\
\hline $\begin{array}{l}\text { East Asia \& } \\
\text { Pacific }\end{array}$ & & & & & & & 23.57 \\
\hline Asia & 3.96 & 3.88 & 3.83 & 3.82 & 3.84 & 3.93 & 23.25 \\
\hline Australia & 4.00 & 4.03 & 4.00 & 4.02 & 3.89 & 3.95 & 23.90 \\
\hline China & 4.09 & 4.01 & 3.98 & 4.04 & 3.95 & 4.06 & 24.13 \\
\hline HongKong & 4.07 & 4.05 & 4.01 & 4.03 & 3.97 & 4.00 & 24.13 \\
\hline Japan & 3.69 & 3.68 & 3.65 & 3.63 & 3.54 & 3.52 & 21.71 \\
\hline NewZealand & 4.00 & 4.00 & 3.93 & 4.25 & 3.86 & 3.83 & 23.87 \\
\hline Singapore & 3.97 & 4.01 & 3.95 & 3.94 & 3.84 & 3.87 & 23.56 \\
\hline Vietnam & 3.98 & 4.00 & 4.07 & 4.10 & 3.85 & 4.03 & 24.03 \\
\hline $\begin{array}{l}\text { Europe \& CeI } \\
\text { Asia }\end{array}$ & & & & & & & 23.96 \\
\hline Cyprus & 3.91 & 4.09 & 3.94 & 3.97 & 3.94 & 3.93 & 23.78 \\
\hline Denmark & 3.78 & 3.78 & 3.44 & 3.63 & 3.22 & 3.33 & 21.18 \\
\hline Europe & 3.93 & 3.95 & 3.90 & 3.93 & 3.75 & 3.85 & 23.31 \\
\hline France & 3.90 & 3.99 & 3.95 & 3.98 & 3.84 & 3.89 & 23.55 \\
\hline Greece & 4.01 & 4.05 & 3.96 & 3.93 & 3.90 & 3.99 & 23.84 \\
\hline Italy & 4.20 & 4.25 & 4.05 & 4.11 & 4.05 & 4.10 & 24.75 \\
\hline Latvia & 3.98 & 3.95 & 3.94 & 4.01 & 3.82 & 3.81 & 23.52 \\
\hline Macedonia & 4.46 & 4.42 & 4.46 & 4.23 & 4.42 & 4.43 & 26.42 \\
\hline Norway & 3.76 & 3.72 & 3.69 & 3.74 & 3.46 & 3.65 & 22.01 \\
\hline Romania & 4.31 & 3.97 & 4.10 & 4.19 & 4.14 & 4.25 & 24.96 \\
\hline Serbia & 4.22 & 4.16 & 4.23 & 4.15 & 4.08 & 4.19 & 25.04 \\
\hline Switzerland & 4.23 & 4.12 & 4.23 & 4.03 & 4.07 & 4.11 & 24.79 \\
\hline Turkey & 4.10 & 4.12 & 4.11 & 4.15 & 4.07 & 4.10 & 24.65 \\
\hline UK & 4.03 & 4.07 & 4.04 & 4.06 & 3.86 & 3.87 & 23.91 \\
\hline Ukraine & 3.94 & 3.95 & 3.94 & 3.98 & 3.88 & 3.94 & 23.63 \\
\hline
\end{tabular}


OXFORD, UNITED KINGDOM

\begin{tabular}{|l|l|l|l|l|l|l|l|}
\hline $\begin{array}{l}\text { Latin America \& } \\
\text { Caribbean }\end{array}$ & & & & & & & $\mathbf{2 3 . 6 1}$ \\
\hline Argentina & 4.06 & 4.06 & 4.03 & 4.10 & 3.96 & 4.03 & 24.22 \\
\hline Bolivia & 3.86 & 3.94 & 3.89 & 3.92 & 3.84 & 3.86 & 23.31 \\
\hline Brazil & 3.93 & 3.98 & 3.92 & 3.74 & 3.85 & 3.88 & 23.30 \\
\hline $\begin{array}{l}\text { Middle East \& } \\
\text { North Africa }\end{array}$ & & & & & & & \\
\hline Israel & 4.16 & 4.20 & 4.24 & 3.79 & 3.98 & 4.36 & $\mathbf{2 4 . 6 8}$ \\
\hline MidEast & 4.16 & 4.15 & 4.08 & 4.08 & 4.08 & 4.08 & 24.72 \\
\hline North America & & & & & & & 24.63 \\
\hline Canada & 4.05 & 4.14 & 4.11 & 4.10 & 3.93 & 4.00 & $\mathbf{2 4 . 4 6}$ \\
\hline USA & 4.11 & 4.15 & 4.11 & 4.14 & 4.02 & 4.05 & 24.33 \\
\hline South Asia & & & & & & & 24.59 \\
\hline Bangladesh & 4.07 & 4.11 & 4.05 & 4.00 & 4.06 & 4.05 & $\mathbf{2 3 . 8 5}$ \\
\hline India & 4.14 & 4.11 & 4.10 & 4.03 & 3.98 & 4.03 & 24.34 \\
\hline Pakistan & 3.84 & 3.84 & 3.77 & 3.83 & 3.75 & 3.79 & 24.38 \\
\hline Sub-Saharan & & & & & & & 22.82 \\
\hline Africa & 4.13 & 4.14 & 4.16 & 4.09 & 4.05 & 4.11 & $\mathbf{2 4 . 2 6}$ \\
\hline Nigeria & 4.00 & 4.01 & 4.00 & 4.03 & 3.91 & 3.92 & 24.67 \\
\hline SouthAfrica & & & & & & & \\
\hline
\end{tabular}

Then, to test the hypotheses the regression models were processed in SPSS and those results are presented in Table 3. The models are presented as follows: the first model included only controls; the second model tested for rater level (e.g. individual contributor, management, executive, etc.); the third model incorporated the other independent variable country developing status, and the final model incorporated all variables. The complete model had an adjusted $\mathrm{R}$ of .008 . 
OXFORD, UNITED KINGDOM

Table 3

Regression Models for analyzing the dependent variable with controls, controls plus rater level (executive vs. not), country status, and with all variables

Results of Regression Analysis

\begin{tabular}{|c|c|c|c|c|c|}
\hline Hypothesis & Variable & Model 1 & Model 2 & Model 3 & Model 4 \\
\hline & Organization & $* * 0.02$ & & $* * 0.03$ & \\
\hline & Nature & & $* * 0.02$ & & $* * 0.03$ \\
\hline & Organization & $* * * 0.05$ & & $* * * 0.04$ & \\
\hline & Type & & $* * * 0.05$ & & $* * * 0.04$ \\
\hline & Raters Years of & $* *_{-} 0.03$ & & $*_{-} 0.02$ & \\
\hline & Experience & & $*_{-} 0.02$ & & $*_{-} 0.02$ \\
\hline & Education & $*_{-0.02}$ & $*_{-0.02}$ & $*_{-0.03}$ & $*_{-} 0.02$ \\
\hline & Rater Sex & $* 0.02$ & 0.02 & $* 0.02$ & 0.02 \\
\hline \multirow[t]{3}{*}{2} & Rater Level & & $* * *_{-} 0.05$ & & $* * *-0.05$ \\
\hline & Country & & & $* *_{*}-0.04$ & \\
\hline & Developing & & & & \\
\hline \multirow[t]{10}{*}{1} & Status & & & & $* * *-0.03$ \\
\hline & Adjusted R & 0.004 & 0.006 & 0.005 & 0.008 \\
\hline & $\mathrm{F}$ & $* * * 9.344$ & $* * * 12.534$ & $* * * 10.163$ & $* * * 12.379$ \\
\hline & & 5 & & & \\
\hline & df & 11017 & $1, \quad 11016$ & $1, \quad 11016$ & $1, \quad 11016$ \\
\hline & The coefficients & & & & \\
\hline & are standardized & & & & \\
\hline & $* \mathrm{p} \leq .05$ & & & & \\
\hline & $* * \mathrm{p} \leq .01$ & & & & \\
\hline & $* * * \mathrm{p} \leq .001$ & & & & \\
\hline
\end{tabular}

In addition to demonstrating the model with the regression, the interaction between country developing status and executive level dummy variable was ran in PROCESS as prescribed in Hayes (2013). The results of that interaction was a coefficient of .007 and 
significant at the $\mathrm{p} \leq .05$ level. The results indicate that Hypothesis 1 and 2 were not supported because the relationship was in the inverse direction. Practitioners from developing countries have higher perceived analytic skills than those from developed countries. The hypothesis that the relationship between strategic level raters, in this case, executives, was not supported with this analysis. However, the modifying effect of developing country status was supported. In conducting an ANOVA to better understand the difference in rater types better, those in executive and management ranked positions have significantly lower scores than others within the 360 . At the same time, those outside the organization reflected the highest perceived analytic scores. These results are provided in Table 4, along with post hoc analysis. This analysis is relative to research recommendations, and further discourse is in the discussion.

\section{Table 4}

ANOVA with descriptive statistics and Tukey HSD post hoc analysis of rater level on the dependent variable analytic scores.

\begin{tabular}{lccccc}
\hline \multicolumn{1}{c}{ Variable } & SS & df & MS & F & p \\
\hline Between Groups & 72.73 & 6 & 12.12 & 27.248 & .00 \\
Within Groups & 6131 & 13783 & .45 & & \\
Total & 6203.9 & 13789 & & & \\
& 2 & & & & \\
\hline
\end{tabular}

\begin{tabular}{lccc}
\hline & \multicolumn{3}{c}{ Subset for $\mathrm{a}=.05$} \\
\cline { 2 - 3 } \multicolumn{1}{c}{ Variable } & 1 & 2 & 3 \\
\hline Executive & 3.91 & & \\
Top Executive & 3.94 & & \\
Management & 3.98 & & \\
Supervisor & & 4.07 \\
Non-supervisor & 4.08 \\
Entry Level & 4.09 & \\
Other & & & 4.21 \\
Sig. & .323 & .999 & 1.00 \\
\hline Note. Means for groups in homogeneous subsets are displayed. Tukey HSD uses
\end{tabular}


harmonic mean sample size $=900.706$.

\section{Limitations/Delimitations}

The research was bound by the dataset of the HRCS results and the World Bank and UN country datasets. The previously noted limitations in the nature of the study (e.g. sampling method), were previously discussed. The analytics question set, intended to be parsimonious, maybe too simple given the specific analytic skillsets valuable for consideration in a fast-moving world of analytics. Tools are changing rapidly with the growth of artificial intelligence (Eubanks, 2019). Further, in addition to advanced technology, quantitative skills are significant to practitioners' defined gap in specific areas such as workforce planning (Safarishahrbijari, 2018). This research also did not address practitioners by functional role, which researchers have argued HR competencies are role-specific (Yeung, Woolcock, \& Sullivan, 1996). Finally, the analysis results indicate that despite significance the model accounts for very little of what contributes to analytic skills $\left(R^{2}=.008\right.$ of the final model). However, this also signifies that the analytics competency may be as universal as implied in the research by Ulrich and colleagues. As such, it is valuable in and of itself in contributing to the research of the analytic competency being fairly universal in HR, no matter western vs. non-western context.

\section{Discussion}

This research was pursued out of diligence to remove assumptions regarding the analytic skill set in the competency models, especially given the emphasis in the discipline to move forward in analytics and provide assurance that we are addressing all practitioners given the internationalization of the firm. The hypotheses, as such, have a narrow focus on this specific skill set. This is the first area suggested for further research; to consider variance of analytic scores compared to other skills related to conflict resolution and bridging cultural divide by developing status. The depth of the impact may be more significant for those skills and demonstrate more variance than analytic skills. Kryscynski et al. (2017) controlled for general business skills and personal credibility, but not these other skills present in research outside the HRCS that have IB implications on HR practitioner skills (Welch \& Welch, 2012; Han et al., 2006). 
Second, the lack of results for the relationship to strategic roles should be assessed differently in hindsight. The ANOVA results indicate those in higher levels may grade differently than those in lower-level positions. Bynum et al. (2013) concluded performance ratings from different sources do not conceptualize performance similarly in multisource performance ratings, which these results support. Therefore, it would be important to understand that variance for executives across all competencies and then study the delta (to control this grading difference) between competencies to best understand which competency is present and performance is higher. Subsequently, one would be able to know if the analytics competency is closer to the strategic vest.

The results that are of most interest are the nuances between developed and developing countries; the results being inversely related than was hypothesized. Those from developing countries demonstrating higher perceived analytic skills are an interesting phenomenon and probably of the most value. There were no indications in previous research that such findings would emerge. Additional research of analytical skill development and use in developing countries would be of value to 1) assess the generalizability of these results, but 2) if practitioners in developing countries are presenting with this skill more consistently. Assuming it's the demand skill of the future, understanding what is unique about practitioners in developing countries that may be putting them slightly ahead of the demand curve would be of value. Research regarding potential rationale such as type of HR (outsourced versus internal) did not provide any insights. The subjective nature of perceived scores may be a factor. An aptitude battery that addresses quantitative, technological, and data inference may be more appropriate to understand this particular skill set best.

\section{Conclusion}

The value of analytic competency in HR is a burgeoning topic. This research dove into the HR practitioner's analytical competency to assess the assumptions within previous research. This topic was worth pursuing because the value of IHRM is also growing. The intersection of competency is of interest to ensure literature informs the firm and contributes to understanding when and where practitioner competencies vary. This research is important for future practitioners' training and development to ensure they are provided value within the firm. Surprisingly, the results indicate that those in developing countries have higher perceived analytic scores than those in developed 
OXFORD, UNITED KINGDOM

countries. This research also provided evidence supportive of rater variance in multisource systems when assessing for analytics in HR. Further research is needed to understand the variance between developed/developing countries and empirically assess what indeed drives analytic skill competency as a whole. 


\section{References}

Autio, E., Sapienza, H., Almeida, J. (2000). Effects of age at entry, knowledge of intensity, and imitability on international growth. Academy of Management Journal, 43(5), 909-924.

Ayentimi, D.T., Burgess, J., \& Brown, K. (2018). HRM development in post-colonial societies: The challenges of advancing HRM practices in Ghana. International Journal of Cross Cultural Management, 18(2), 125-147. https://doiorg.portal.lib.fit.edu/10.1177/1470595818765863

Barney, J. B., \& Wright, P. M. (1998). On becoming a strategic partner: The role of human resources in gaining competitive advantage. Human Resource Management (1986-1998), 37(1), 31. https://search-proquestcom.portal.lib.fit.edu/docview/224323931 accountid=27313

Baron, R. M., Kenny, D.A. (1986). The moderator-mediator variable distinction in social psychological research: Conceptual, strategic, and statistical considerations. Journal of Personality and Social Psychology, 51(6), 1173-1182. http://dx.doi.org.portal.lib.fit.edu/10.1037/0022-3514.51.6.1173

Bassi, L., Carpenter, R., \& McMurrer, D. (2010). HR analytics handbook: Report of the state of knowledge. Amsterdam: Reed Business.

Boudreau, J.W., \& Ramstad, P.M. (2007). Beyond HR: The New Science of Human Capital. Harvard Business School Press: Boston, MA.

Bynum, B.H., Hoffman, B.J., Meade, A.W., \& Gentry, W.A. (2013) Reconsidering the equivalence of multisource performance ratings: Evidence for the importance and meaning of rater factors. Journal of Business and Psychology, 28, 203-219. https://doi-org.portal.lib.fit.edu/10.1007/s10869-012-9272-7

Caudron, S. (2004, April). Jac Fitz-enz, metrics maverick. Workforce. https://www.workforce.com/2004/04/01/jac-fitz-enz-metrics-maverick/

Coetzer, A., \& Sitlington, H. (2013). What knowledge, skills and attitudes should strategic HRM student acquire? A Delphi study. Asia Pacific Journal of Human Resources, 52(2), 155-172. https://doi-org.portal.lib.fit.edu/10.1111/17447941.12008

De Bruecker, P., Van den Bergh, J., Belien, J., Demeulemeester, E. (2015). Workforce 


\section{OXFORD, UNITED KINGDOM}

planning incorporating skills: State of the art. European Journal of Operational Research, 243(1), 1-16. https://www-sciencedirectcom.portal.lib.fit.edu/science/article/pii/S0377221714008601

Eubanks, B. (2019). Artificial Intelligence for HR: Use AI to support and develop a successful workforce. New York, NY: Kogan Page.

Farndale, E., Scullion, H. \& Sparrow, P. (2010). The role of the corporate HR function in global talent management. Journal of World Business, 45(2), 161-168.

Fitz-enz, J. (2010). The new HR analytics: Predicting the economic value of your company's human capital investments. Broadway, NY: AMACOM

Foley, S., Ngo, H-Y., \& Loi, R. (2012). The adoption of high performance work systems in foreign subsidiaries. Journal of World Business, 47(1), 106-113. https://doi.org/10.1016/j.jwb.2010.10.025

Fraley, R.C., \& Vazire, S. (2014). The N-pact factor: evaluating the quality of empirical journals with respect to sample size and statistical power. PLOS One, 9(10). https://doi.org/10.1371/journal.pone.0109019

Griffith, D.A., Cavusgil, S.T., \& Xu, S. (2008). Emerging themes in international business research. Journal of International Business Studies, 39, 1220-1235.

Han, J., Chou, P., Chao, M., \& Wright, P. (2006). The HR competencies-HR effectiveness link: A study in Taiwanese high-tech companies. Human Resource Management, 45(3), 391-406. https://doi-org.portal.lib.fit.edu/10.1002/hrm.20114

Hayes, A.F. (2013). Introduction to Mediation, Moderation, and Conditional Process Analysis: A Regression-Based Approach (2 $\left.{ }^{\text {nd }}\right)$. Guilford Press. New York, NY.

Hersey, P., \& Blanchard, K. (1969). Life cycle theory of leadership. Training and Development Journal, 23, 26-35

Johanson, J., \& Vahlne, J. (2009). The Uppsala internationalization process model revisited: From liability of foreignness to liability of outsidership. Journal of International Business $\quad$ Studies, 40(9), 1411-1431. http://dx.doi.org.portal.lib.fit.edu/10.1057/jibs.2009.24

Kaufman, B.E. (2014). The historical development of American HRM broadly viewed. Human Resource Management Review, 24, 196-218. http://dx.doi.org/10.1016/j.hrmr.2014.03.003.

Kryscynski, D., Reeves, C., Stice-Lusvardi, R., Ulrich, M., \&Russell, G. (2017). Analytical abilities and the performance of HR professionals. Human Resource 
Management, $\quad$ 57(3), $\quad$ 715-738. https://doiorg.portal.lib.fit.edu/10.1002/hrm.21854

LaFevor, K. (2018). HR practitioners as 'strategic asset decision makers': Not a business partner, but 'part of the business'. HR Professionals Magazine, 8(4), 26-27.

Lawler, E.E. III, \& Boudreau, J.W. (2015). Global Trends in Human Resource Management: A Twenty-Year Analysis. Stanford University Press: Stanford, CA. Lengnick-Hall, M.L., Lengnick-Hall, C.A., Andrade, L.S., Drake, B. (2009). Strategic human resource management: The evolution of the field. Human Resource Management Review, 19(2), 64-85. https://doi.org/10.1016/j.hrmr.2009.01.002

Levenson, A. \& Alexis, F. (2017). Human capital analytics: Too much data and analysis, not enough models and business insights. Journal of Organizational Effectiveness, $4(2)$, $145-156$. https://search-proquestcom.portal.lib.fit.edu/docview/2080939917?accountid=27313\&pqorigsite $=$ summon

Lockwood, N.R., Woolever, N.A., Alonso, A., Jones, J.A., Northon, L., \& American Institutes for Research. (2018). SHRM human resource curriculum: Guidebook and templates for undergraduate and graduate programs. Society for Human Resources Management: Alexandria, VA.

Lunsford, D.L., \& Phillips, P.P. (2018). Tools used by organizations to support human capital analytics. Performance Improvement, 57(3), 6-15. https://doi.org/10.1002/pfi.217

Maurer, R. (2018). The C-suite lacks confidence in HR data analytics but why?: Majority of executives say blame for faulty analytics lies with I.T. HRNews, Retrieved from https://search-proquestcom.portal.lib.fit.edu/docview/2017416000? accountid=27313

Mamman, A., \& Al Kulaiby, K.Z. (2014). Is Ulrich's model useful in understanding HR practitioners' roles in non-western developing countries? An exploratory investigation across private and public sector organizations in the Sultanate Kingdom of Oman. The International Journal of Human Resource Management, 25(20), 2811-2836. https://doiorg.portal.lib.fit.edu/10.1080/09585192.2014.914053

Prikshat, V., Biswas, K., Nankervis, A., \& Hoque, M. R. (2018). Bangladesh HR professionals' competencies. Evidence - Based HRM, 6(2), 203-220. 


\section{OXFORD, UNITED KINGDOM}

doi:http://dx.doi.org.portal.lib.fit.edu/10.1108/EBHRM-12-2017-0064

Safarishahrbijari, A. (2018). Workforce forecasting models: A systematic review. Journal of Forecasting, 37(7), 739-753. Retrieved from https://onlinelibrarywiley-com.portal.lib.fit.edu/doi/full/10.1002/for.2541

Sanchez, J.I., \& Levine, E.L. (2009). What is (or should be) the difference between competency modeling and traditional job analysis? Human Resource Management Review, 19(2), 53-63. https://doi.org/10.1016/j.hrmr.2008.10.002

Scanlan, K.E. (2007). University human resource management curriculum and human resource management competencies: A comparative study. [Doctoral dissertation, Capella University]. https://search-proquestcom.portal.lib.fit.edu/docview/304721701?pqorigsite $=$ summon $\&$ accountid $=27313$

Schuler, R.S., \& Jackson, S.E. (2005). A quarter-century review of Human Resource Management in the US: The growth in importance of the international perspective. Management Review, 16(1), 11-35. https://www-jstororg.portal.lib.fit.edu/stable/41782023

Sinar, E., Ray, R.L., \& Canwell, AL (2018, October 25). HR leaders need stronger data skills. Harvard Business Review Digital Articles. web.a.ebscohost.com.portal.lib.fit.edu/ehost/pdfviewer/pdfviewer?vid=3\&sid=2 8e4d401-fa5d-4ef0-a767-90f8f93fc62b\%40sessionmgr4007

Society for Human Resources Management (2016). The SHRM Competency Model. https://www.shrm.org/LearningAndCareer/competencymodel/PublishingImages/pages/default/SHRM\%20Competency\%20Model_Det ailed\%20Report_Final_SECURED.pdf

Soundararajan, R. \& Singh, K. (2017). Winning on HR Analytics: Leveraging Data for Competitive Advantage. Thousand Oaks, CA: Sage Publications Inc.

Sumaramaniam, A., \& Nankervis, A. (2013). Strategy agility and the role of HR as a strategic business partner: an Indian perspective. Asia Pacific Journal of Human Resources, 51(4), 454-470. https://doi-org.portal.lib.fit.edu/10.1111/17447941.12004

Tessema, M.T., \& Soeters, J.L. (2007). Challenges and prospects of HRM in developing countries: Testing the HRM-performance link in the Eritrean civil service. The International Journal of Human Resource Management, 17(1), 86-105. 


\section{OXFORD, UNITED KINGDOM}

https://doi-org.portal.lib.fit.edu/10.1080/09585190500366532

Ulrich, D., Brockbank, W., Ulrich, M., \& Kryscynski, D. (2015). Toward a synthesis of HR competency models: The common HR "food groups". People \& Strategy, $38(4)$, 56-65. https://link-galecom.portal.lib.fit.edu/apps/doc/A552253055/AONE?u=melb26933\&sid=AONE $\& \mathrm{xid}=3 \mathrm{c} 5 \mathrm{f} 429 \mathrm{~d}$

Ulrich, D., \& Dulebohn, J.H. (2015). Are we there yet? What's next for HR? Human Resource Management Review, 25(2), 188-204. https://doi.org/10.1016/j.hrmr.2015.01.004

Ulrich, D., Younger, J., \& Brockbank, W. (2008). The twenty- first- century HR organization. Human Resource Management, 47(4), 829-850.

Ulrich, D., Younger, J., \& Brockbank, W. (2012). HR competency. Leadership Excellence, 29(8), 17.

Ulrich, D., Younger, J., Brockbank, W., \& Ulrich, M. (2012). HR talent and the new HR competencies. Strategic HR Review, 11(4), 217-222. http://dx.doi.org.portal.lib.fit.edu/10.1108/14754391211234940

United Nations (UN) (2019). World Economic Situation and Prospects 2019. https://www.un.org/development/desa/dpad/wpcontent/uploads/sites/45/WESP2019_BOOK-ANNEX-en.pdf

Vargas, R., Yurova, Y.V., Ruppel, C.P., Tworoger, L.C., \& Greenwood, R. (2018). Individual adoption of HR analytics: A fine grained view of the early stages leading to adoption. The International Journal of Human Resource Management, 29(22), 3046-3067. https://doiorg.portal.lib.fit.edu/10.1080/09585192.2018.1446181

Voermans, M., \& Veldhoven, M. (2007). Attitudes towards E-HRM: An empirical study at Philips. Personnel Review, 36(6), 887-902. http://dx.doi.org.portal.lib.fit.edu/10.1108/00483480710822418

Vroom, V. H. (1964). Work and motivation. New York: Wiley.

Welch, C.L., \& Welch, D.E. (2012). What do HR managers really do? HR roles on international projects. Management International Review, 52, 597-617. https://doi-org.portal.lib.fit.edu/10.1007/s11575-011-0126-8

The World Bank (2020). The World Bank: Data: GNI (current US\$). https://data.worldbank.org/indicator/NY.GNP.MKTP.CD 
3rd International Conference on BUSINESS,

MANAGEMENT AND FINANCE

OXFORD, UNITED KINGDOM

Wright, P. M., McMahan, G. C., Snell, S. A., \& Gerhart, B. (2001). Comparing line and HR executives' perceptions of HR effectiveness: Services, roles, and contributions. Human Resource Management, 40, 111-123. https://doi.org/10.1002/hrm.1002

Yeung, A.K., Woolcock, P., \& Sullivan, J. (1996). Identifying and developing HR competencies for the future: Keys to sustaining the transformation of HR functions. Human Resource Planning, 19(4). 48-58. https://search-proquestcom.portal.lib.fit.edu/docview/224585312?accountid=27313 